\title{
Efficient and sustainable environmental management as a means of addressing current pollution issues
}

\author{
Dino Musmarra $^{1} \cdot$ Antigoni Zafeirakou $^{2} \cdot$ Vasiliki Manakou $^{2} \cdot$ Christina Emmanouil $^{3}$
}

Received: 5 February 2019 / Accepted: 12 April 2019 / Published online: 25 April 2019

(C) Springer-Verlag GmbH Germany, part of Springer Nature 2019

In recent years, new challenges in environmental management have arisen; old threats have not been eradicated while emerging hazards and risks have already established their presence. The ongoing quest for a cleaner and safer environment supporting society and economy can only be achieved through a visionary strategy focused on sustainable development, resource efficiency, universal transparency, trust, and partnership. Despite local improvements in sanitation and decontamination as well as implementation of stricter and broader environmental policies, societies must deal with climate change and harsher climatic conditions, water scarcity, global pollution and emergence of new pollutants to name a few. Since traditional tools of investigation and exploration are probably now insufficient in addressing these problems, new collaboration and partnerships are needed; the present compilation of works aspires to present aspects of environmental research and to propose a novel "way-forward."

Responsible editor: Philippe Garrigues

Christina Emmanouil

chemmanouil@plandevel.auth.gr

Dino Musmarra

dino.musmarra@unicampania.it

Antigoni Zafeirakou

azafir@civil.auth.gr

Vasiliki Manakou

vmanak@ civil.auth.gr

1 Department of Engineering, Polytechnic and Basic Science School, University of Campania "Luigi Vanvitelli", Aversa, Italy

2 School of Civil Engineering, Faculty of Engineering, Aristotle University of Thessaloniki, Thessaloniki, Greece

3 School of Spatial Planning and Development, Faculty of Engineering, Aristotle University of Thessaloniki, Thessaloniki, Greece
The special issue of Environmental Science and Pollution Research you hold in your hands is a collection of 12 papers initially presented at the 6th International Conference on Environmental Management, Engineering, Planning and Economics (CEMEPE 2017) and SECOTOX Conference. The conference was held on 25th to 30th of June, 2017, in Thessaloniki, Greece (http://cemepe6.civil.auth.gr/). The conference was organized by the Division of Hydraulics and Environmental Engineering of the Department of Civil Engineering of Aristotle University of Thessaloniki, the Sector of Industrial Management and Operations Research of the School of Mechanical Engineering of National Technical University of Athens, the Department of Civil Engineering of University of Thessaly and the Food Technology Department of Technological Educational Institute of Thessaloniki. The conference was the 6th from a successful series of CEMEPE/ SECOTOX conferences where scientists from all around the world exchange ideas and knowledge on all aspects of environmental management and share experience and expertise towards common and viable solutions.

The manuscripts included in the present Special Issue are based on the ones initially presented at the CEMEPE2017/ SECOTOX conference; however, they have been extended (by at least 50\%) and they have undergone the rigorous peer-review process of the journal until acceptance. The topics that the papers included in the current issue focus on are briefly presented below:

True to the ecotoxicological origins of SECOTOX, the research of Kachenton et al. focuses on the toxicity of titanium nanoparticles to the model organism Artemia salina, revealing interesting histopathological findings. Furthermore, the review of Ziegler gives valuable insights on the strengths and limitations of using duckweeds for determination of ecotoxicological hazard and risk for freshwater environments. Polluted aquatic reservoirs were also central in the research of Dong et al., who investigated metal profiles in a highly 
industrialised coastline in Taiwan revealing that the harbour sediments posed a very high ecological risk, while coastal wastewaters in Eastern Mediterranean Sea were the principal research field in Tugrul et al. study; the authors examined the applicability of current tools for determination of trophic status and reached important conclusions on their classification which is pivotal for their subsequent management. Water management plans for rivers and lakes were critically assessed by Skoulikaris and Zafirakou, using four transboundary river basins in Southern Europe as the case study, highlighting the need for shared and reliable data between neighbouring countries. Environmental pollution may be addressed through the design and application of modern waste treatment facilities; as such the odour nuisance from a municipal solid waste landfill in Italy was effectively forecasted by Di Nardo et al., simplifying the need for precautionary measures. Furthermore, the sustainability of other large infrastructures, such as water treatment facilities in Turkey, were evaluated in detail in the study of Saad et al., utilizing the life-cycle assessment approach. Organic waste and the amelioration of its management were investigated in the study of Loizia et al., which showed encouraging results through co-digesting of food waste and other wastes in existing anaerobic treatment plants. However, very little in application of circular economy schemes can be achieved without active stakeholder participation; the study of Lazaridou et al. eloquently quantifies this requisite, through investigation of Greek farmers' willingness to undertake the environmental costs arising from their activity. Finally, in the research field of new technologies for efficient environmental protection, a greener solvent was successfully tested for the preparation of polymeric membranes in the study of Marino et al., while the improvement of a carbon black composite material used for toluene decontamination was efficiently created through the modifications described in Dong et al. Last but not least, a novel herbal biocide from Tinospora crispa was tested against mosquito larvae, in the study of Jiraungkoorskul proving that solutions in persisting problems may be closer than we think and may indeed be found in the natural environment.

Publisher's note Springer Nature remains neutral with regard to jurisdictional claims in published maps and institutional affiliations.

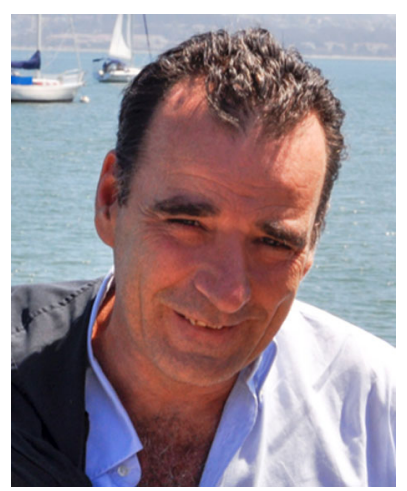

Dr. Dino Musmarra is a full professor of Chemical Plants at the Department of Engineering of the Polytechnic and Basic Science School of the University of Campania "Luigi Vanvitelli," Aversa, Italy. He graduated cum laude in Chemical Engineering in 1984 from Università di Napoli "Federico II" (Naples, Italy) and received his $\mathrm{PhD}$ in Chemical Engineering in 1989 from University of Naples "Federico II" (Naples, Italy). His research activity includes various fields, among which the most recent are protection of groundwaters by permeable adsorptive barriers; wastewater treatment by AOP, innovative renewable fuel technologies, microalgal biomass growth, and biotransformation for valuable by-product production and extraction. During his 30-year research career, he has served as principal investigator in 16 projects, funded with more than $€ 4 \mathrm{M}$. He has published more than 150 papers in international peer-reviewed journals and more than 200 papers in international conferences. His papers have been cited more than 2700 times in journal publications $(\mathrm{H}$-index $=34)$.

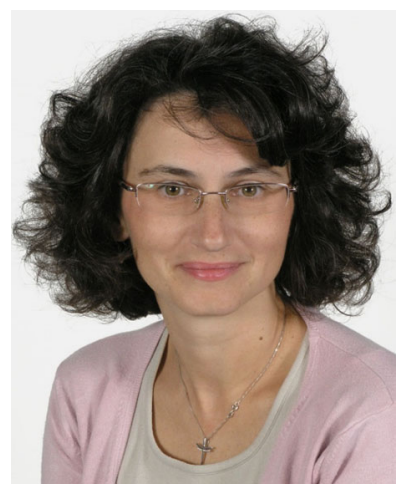

Dr. Antigoni Zafirakou is an Assistant Professor at the School of Civil Engineering, Faculty of Engineering, Aristotle University of Thessaloniki. She holds a PhD in Civil \& Environmental Engineering, from Tufts University, USA; MSc in Civil \& Environmental Engineering, from the University of Connecticut, USA. She is the author of three chapters in books: Sustainable urban water management, in "City Networks," SpringerLink; Oil spill dispersion forecasting models, in "Monitoring of Marine Pollution," InTech Open Access and Hydrologic record events, in "Applications of Statistical Distributions in Hydrologic Sciences and Engineering," ASCE. She has numerous published papers in peer-reviewed journals and conference papers, with more than 100 citations, served as an editor in one Special Issue (Fresenius Environmental Bulletin) and she is a member of Organizing and Scientific Committees of International Conferences and a member of Unesco-INWEB. 


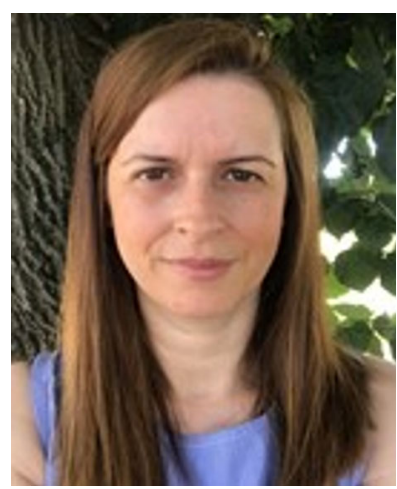

Dr. Vasiliki Manakou is a research associate at the School of Civil Engineering, AUTH, Greece. She has received her Bachelor degree in Forestry and Natural Environment from AUTH, her M.Sc. in Protection and Restoration of the Environment from University of Edinburgh, Scotland and her $\mathrm{Ph}$.D. in Water Resources Management form University of Thessaly (UTH), Greece. She has published 3 papers in peerreviewed journals, has taken part in more than 25 research projects in AUTH, UTH, and National Technical University of Athens. Her research interests include environmental management and water resources management.

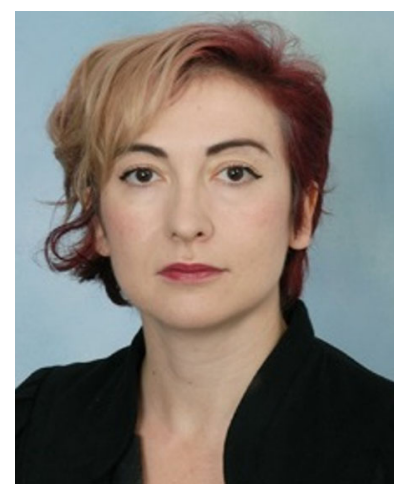

Dr. Christina Emmanouil works as a lecturer at the School of Spatial Planning and Development, Aristotle University of Thessaloniki (AUTH). She has received her Bachelor degree from National Hellenic University of Athens and her post-graduate degrees in Environmental Sciences from the University of Birmingham, UK. Her previous tasks included being an environmental risk assessor for Plant Protection Products and their substances according to Dir.91/414/EEC and Reg.1107/2009/EC and for biocides according to Dir.98/8/EC for Greek Ministry of Agriculture (Benaki Phytopathological Institute, BPI), a lecturer and a research associate in various environmental-related projects. Her current work involves waste management options and their effects on humans and the ecosystem. She has published 19 papers in peer-reviewed journals, has taken part as an investigator or principal investigator in more than 25 projects in AUTH, BPI, University of Thessaly and Agricultural University of Athens, and worked as a regional manager for Toxicological and Environmental Chemistry journal (2016-2018). 